\title{
SEM Model in Analysis of the Relationship of Severity Diagnosis with Breast Cancer Recovery
}

\author{
M. Nadjib Bustan, M. Arif Tiro, Suwardi Annas, Bobby Poerwanto
}

\begin{abstract}
Diagnosis of the severity of breast cancer has a series of relationships with the prognosis of recovery along with factors of patient history, severity, treatment, and nursing. The problem is how the pattern of relationships between all these factors. This study aims to figure out the pathway model of the relationship between the severities of breast cancer with recovery along with other related factors. Modeling of SEM (Structural Equation Modeling) drew204 patients diagnosed with breast cancer in Makassar hospitals during 2018. Data were collected from the Medical Record, Hospital Information System, and hospital pathology diagnosis. Data analyzed consisted of severity as exogenous variable, recovery as endogenous variable, and latent variables along with their indicators: medical history, clinical diagnosis and pathological diagnosis (topography, grade, behavior), treatment, and nursing factors. The result of SEM in measurement model test between severity and pathology diagnosis indicators found the probability values: severity with grade ( $p$ value 0.001), behavior ( $p$ value 0.275), and topography ( $p$ value 0.276).Structural model test between severity and recovery got a probability value of 0.336.The suitability test of the model found Chi-square value of 213,657, df 53, p value 0.001; CMIN/DF 44.031; RMSEA 0.122. Correlation test between patient history and severity 0.037; nursing with severity of -0.070 ; and history of patients with nursing -0.024. The structural model test do not show a significant effect of severity toward recovery; the suitability test of the model is less able to explain its suitability with the data; and the correlation test is weak. The suggestion for remodeling to get suitable model which supported by empirical data.
\end{abstract}

Keyword: SEM, diagnosis, severity, recovery, breast cancer.

\section{INTRODUCTION}

As a chronic disease, the natural history of breast cancer is a long process. Breast cancer patient is a person who was initially healthy, had cancer, and was diagnosed with breast cancer. Furthermore, breast cancer patients will receive treatment and care to the prognosis choices that will occur. How the prognosis of breast cancer patients will be interrelated with the patient's medical history, diagnosis status, treatment and care obtained [1].

The prevalence of breast cancer takes place in the top position in women cancer throughout the world and is increasing especially in developing nations where most cases are diagnosed in the final status. Although breast cancer is

Revised Manuscript Received on January 2, 2020.

M. Nadjib Bustan*, Department of Statistics, Universitas Negeri Makassar, Makassar City, Indonesia. Email : mnbustan@unm.ac.id

M. Arif Tiro, Department of Statistics, Universitas Negeri Makassar, Makassar City, Indonesia. Email: arif_tiro@unm.ac.id

Suwardi Annas, Department of Statistics, Universitas Negeri Makassar, Makassar City, Indonesia. Email: suwardi_annas@unm.ac.id

Bobby Poerwanto, Department of Informatics Engineering, Universitas Muslim Indonesia, Makassar, Indonesia. Email: bobbybp89@gmail.com considered a disease in developed countries, nearly $50 \%$ of breast cancer cases and $58 \%$ of deaths happen in less developed countries. Incidence rates vary widely around the world from 19.3 per 100,000 women in East Africa to 89.7 per 100,000 women in Western countries [2]. Breast cancer ranks second in Asia. Indonesia has the highest prevalence of breast cancer compared to other diseases and non-communicable diseases [3]. Patients diagnosed with breast cancer hope for a cure or a good prognosis. To improve the prognosis, early diagnosis and appropriate treatment are needed [4]. Delay in diagnosis will worsen the prognosis [5]. Breast cancer can be diagnosed clinically, radiological diagnosis and pathological diagnosis [6]. Diagnosis of breast cancer varies in types and classification [7].

To get an accurate diagnosis, the world of medical technology has experienced a very rapid development [8]. In addition to the early diagnosis, treatment factor plays the role in determining prognosis. The type of treatment and improvement in the quality of treatment experienced rapid development [9]. In addition, the size of the tumor and the presence of metastasis also affected the prognosis [10],[11]. The relationship between the diagnosis factor or the severity of the disease with the prognosis of breast cancer along with various related factors can be analyzed using a model SEM (Structural Equation Modeling) [12],[13]. SEM is a multivariate analysis method used in the development of a relationship pattern between one or more independent variables with one or more dependent variables, both continuous and category scale [14]. SEM modeling has been used in various fields of sciences, including health and medicine [15]. Various studies of cancer have been carried out using SEM. Especially regarding breast cancer, also found several studies, but still rare [16].

In this study, the SEM model was used to illustrate the pattern of relationships between medical history and patient risk factors, type of diagnosis, severity of diagnosis, treatment and care provided with the prognosis of recovery expectation.

Declined from the database of journal and publishing house. It is noted that: 1 . Each author profile along with photo (min 100 word) has been included in the final paper. 2. Final paper is prepared as per journal the template. 3. Contents of the paper are fine and satisfactory. Author (s) can make rectification in the final paper but after the final submission to the journal, rectification is not possible. 


\section{MATERIAL AND METHODS}

The study population came from the patients who referred to enter the hospital originating from South Sulawesi Province and various other provinces in eastern Indonesia. Samples were taken from all patients hospitalized during the year of 2018 as many as 204 people were diagnosed with breast cancer. Data is taken from the Hospital Information System (SIRS), an online medical record system that contains various information on factors and variables related to breast cancer patients. Specifically, for the diagnosis of pathology, the data was obtained from the data collection system for the pathology diagnosis sheet of the hospital's Pathology Department. The contents of this data source are integrated to prepare the analysis.

Data collected contains variables from the patient's medical history or risk factors (age, patient status), clinical diagnosis (tumor location, malignancy status, and metastasis), and pathological diagnosis (topography, grade, behavior), treatment given (surgery or chemotherapy), nursing factors (length of stay, class of nursing), and hospital discharge status (cured, improved, died). Diagnosis of the severity of breast cancer has a series of relationships with healing along with factors of patient history, severity, treatment, and nursing. Therefore, it is necessary to identify how the pattern of relationships between these factors.

This study purposes are to determine the pathway model between the diagnosis of breast cancer severity and the prognosis for recovery along with four other related factors. Data analyzed consisted of several variables, namely the severity as an exogenous variable, recovery as an endogenous variable, and five latent variables along with their indicators: health history factors (age, patient status), clinical diagnosis (tumor location, malignancy status, and metastasis), and pathology diagnosis (topography, grade, behavior), treatment given (surgery, chemotherapy), and nursing factors (length of stay, and class of care).

Data analysis uses Structural Equation Modeling (SEM) which analyzes the pattern of relationships between patient factors, the type of clinical diagnosis and pathology, the severity, nursing factors, and treatment given with the patient's recovery prognosis. For this reason, the measurement model test, the structural model test, and the model fit test, and the correlation test between latent variables are performed. The results of path analysis (SEM) are shown in Figure 1.

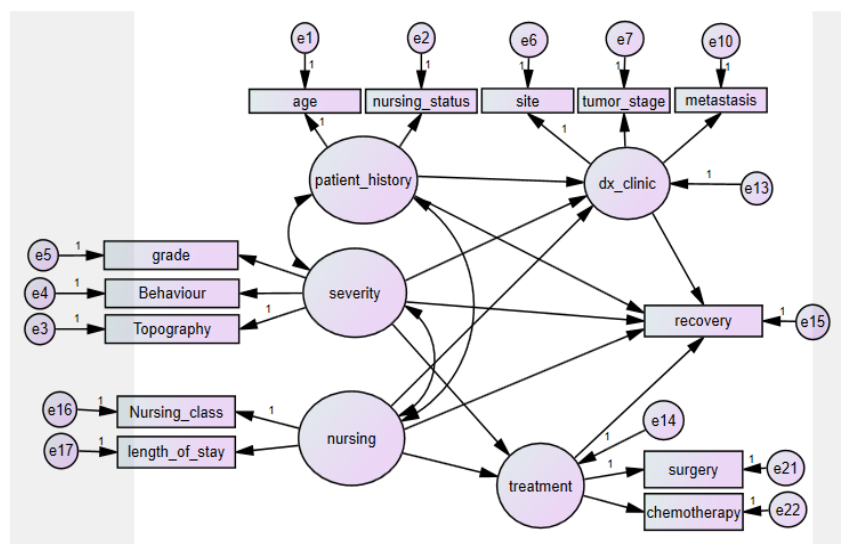

Fig.1. SEM Model Relationship of Severity Diagnosis and Recovery of Breast Cancer

\section{RESULTS AND DiSCUSSION}

To test the accuracy of SEM models, the measurement model test, structural model test, and model fit test, and correlation test between latent variables have been done.

The measurement model test results between the severity variables and their indicators found CFA (Confirmatory Factor Analysis) with the probability value of severity with grade $(\mathrm{p}=0.001)$, with behavior $(\mathrm{p}=0.275)$, and with topography $(\mathrm{p}=0.276)$. This showed that the grade indicator was related to severity, but the behavior and topography indicators did not have a significant relationship with the exogenous severity variable.

Structural model test results between the variables of exogenous severity with endogenous recovery found the $p$ value $=0.336$ (Estimate -1.994 ; Critical Ratio -0.962). These results indicated that it was not proven that severity affects the likelihood of recovery for breast cancer patients.

The model fit test found the Goodness of Fit Chi-square value 213,657 (df 53, and probability level 0.001); and the AGFI (Adjusted Goodness-of-Fit-Index) value of 0.787 (significant level >0.90). Other Model Fit Tests obtained CMIN 213,657 results (df 53, p value 0.001), and obtained CMIN / DF (The Minimum Sample Discrepancy Function divided with Degree of Freedom) of 4,031 (significant level < 0.05); RMSEA (Root Mean Square Error of Approximation) of 0.122 (significant level <0.08), and RMR (Root Mean Square Residual) of 0.955 (significance level <0.05).

Table-I: Model Fit Test Result

\begin{tabular}{|l|c|c|c|c|c|c|}
\hline \multicolumn{1}{|c|}{ Model } & CMIN & Df & CMIN/Df & RMSEA & AGFI & RMR \\
\hline $\begin{array}{l}\text { Default } \\
\text { Model }\end{array}$ & 213.657 & 53 & 4.031 & 0.122 & 0.787 & 0.955 \\
\hline $\begin{array}{l}\text { Saturated } \\
\text { Model }\end{array}$ & -- & -- & -- & -- & -- & 0.001 \\
\hline $\begin{array}{l}\text { Independent } \\
\text { Model }\end{array}$ & 645.675 & 78 & 8.278 & 0.189 & 0.622 & 0.941 \\
\hline
\end{tabular}

Correlation test found a correlation value between latent variables where the patient's historical correlation value with severity 0.037 ; nursing with severity $-0,070$; and history of patients with nursing -0.024 .

The measurement model test results did not show a significant relationship between indicators (behavior and topography) with their latent variables. This is probably due to the diagnosis of this pathology does not describe the severity of breast cancer.

Structural model test results indicate that the severity does not affect the likelihood of recovery from breast cancer patients. This means that diagnosis based on pathology diagnosis is not very important in predicting recovery. Besides that, the treatment factor also does not affect recovery. Therefore, it appears that this model is not supported by existing data.

The situation of the model that is not fit is supported by several results of the fit model (CCMIN / DF, AGFI, RMSEA and RMR) which are not significant. In addition, the correlation test found correlation values between latent variables with low severity or weak correlations. 


\section{Conclusion}

It was concluded that the measurement model test showed that the exogenous variable did not have a significant relationship with the indicator, the structural model test did not show the significant effect of the exogenous severity variable on recovery; the suitability test of the model shows that this model lacks support from the data; and correlation test between exogenous variables and latent variables has weak correlation.

Therefore, it is recommended to do remodeling to get a more appropriate and significant relationship pattern. In addition, elimination of outliers, transformation of the scale size of variables, addition of samples, changes in the selection of indicators to latent variables, further analysis using more specialized sub models, and other options replace the AMOS analysis program with Smart PLS.

\section{ACKNOWLEDGMENT}

Thank you for the financial support from the Indonesian Directorate General of Research and Development Strengthening (DRPM) of the Ministry of Research, Technology and Higher Education, and the Institute of Research and Community Service (LPPM) Universitas Negeri Makassar for all administrative and technical assistance in carrying out this research.

\section{REFERENCES}

1. Elston CW, Ellis IO. pathological prognostic factors in breast cancer. I. The value of histological grade in breast cancer: experience from a large study with long-term follow-up. Histopathology. 1991 Nov 1;19(5):403-10.

2. IARC. New Global Cancer Data: GLOBOCAN 2018 [Internet]. WHO 2018 [cited 2019 Sep 8]. Available from: https://www.uicc.org/news/new-global-cancer-data-globocan-2018

3. Youlden, Danny R., Cramb,Susanna M., Yip,Cheng Har., Baade PD. Incidence and mortality of female breast cancer in the Asia-Pacific region. Cancer Biol Med. 2014 Jun;11(2):101-15.

4. Giordano SH, Buzdar AU, Smith TL, Kau S-W, Yang Y, Hortobagyi GN. Is breast cancer survival improving? Cancer. 2004 Jan 1;100(1):44-52.

5. Brenner DR, Brockton NT, Kotsopoulos J, Cotterchio M, Boucher BA, Courneya KS, et al. Breast cancer survival among young women: a review of the role of modifiable lifestyle factors. Cancer Causes Control. 2016 Apr 12;27(4):459-72.

6. Sinn H-P, Kreipe H. A Brief Overview of the WHO Classification of Breast Tumors, 4th Edition, Focusing on Issues and Updates from the 3rd Edition. Breast Care (Basel). 2013 May;8(2):149-54.

7. WHO. ICD-O INternasional Classification of Diseases for Oncology. Third Edit. Geneva: World Health Oraganization;

8. Sharma GN, Dave R, Sanadya J, Sharma P, Sharma KK. Various types and management of breast cancer: an overview. J Adv Pharm Technol Res. 2010 Apr;1(2):109-26.

9. Masic I, Miokovic M, Muhamedagic B. Evidence based medicine - new approaches and challenges. Acta Inform medica AIM J Soc Med Informatics Bosnia Herzegovina . 2008;16(4):219-25.

10. Abner AL, Collins L, Peiro G, Recht A, Come S, Shulman LN, et al. Correlation of tumor size and axillary lymph node involvement with prognosis in patients with T1 breast carcinoma. Cancer. 1998 Dec 15;83(12):2502-8.

11. Lee AHS. The histological diagnosis of metastases to the breast from extramammary malignancies. J Clin Pathol. 2007 Dec;60(12):1333-41.

12. Hair JF. Multivariate data analysis. Prentice Hall; 2010. 785 p.

13. Edi Riadi. Statistics of SEM Structural Equation Modeling. Yogyakarta: Publisher Andi; 2018 (in Indonesian).

14. Byrne BM. Structural equation modeling with AMOS : basic concepts, applications, and programming. Routledge; 2010. 396 p.

15. Liu X, Wall MM, Hodges JS. Generalized spatial structural equation models. Biostatistics. 2005 Oct 1;6(4):539-57.

16. Vos PJ, Garssen B, Visser AP, Duivenvoorden HJ, de Haes HCJM.
Early Stage Breast Cancer: Explaining Level of Psychosocial Adjustment Using Structural Equation Modeling. J Behav Med. 2004 Dec;27(6):557-80.

\section{AUTHORS PROFILE}

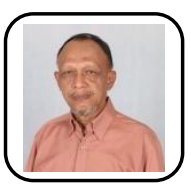

M. Nadjib Bustan, is professor in Department of Statistics, Faculty of Mathematics and Natural Sciences, Universitas Negeri Makassar, Makassar City, Indonesia. He received his Master (MPH) and Doctoral (Dr.PH) in Epidemiology at School of Public Health, University of South Carolina, Columbia, US. He has teaching and research experience in Epidemiology, Biostatistics and Sports Science.

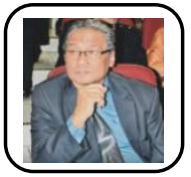

M Arif Tiro is professor in Department of Statistics, Faculty of Mathematics and Natural Sciences. Universitas Negeri Makassar, Makassar City, Indonesia. He received his Master Mathematics Education (M.Sc) and Doctoral (Ph.D) in Iowa State University. He has teaching and research experience in Mathematics Education and Statistical Modeling.

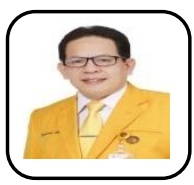

Suwardi Annas is Associate Professor in Department of Statistics, Faculty of Mathematics and Natural Sciences, Universitas Negeri Makassar, Makassar City, Indonesia. He received his Master in Statistics (M.Sc) in Insitut Pertanian Bogor and Doctoral (Ph.D) in Environmental Statistics at Osaka Prefecture University, Japan. He has teaching and research experience in Climate changes prediction.

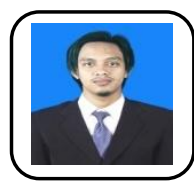

Bobby Poerwanto is lecturer in Department of Informatics Engineering, Faculty of Engineering. Universitas Muslim Indonesia, Makassar City, Indonesia. He received his Master in Statistics Insitut Teknologi Sebelas Maret. He has teaching and research experience in Statistical Modeling \& Machine Learning. . 